\title{
Effect of Oxygen and Nitrogen Limitation on Poly- $\beta$-hydroxybutyrate Biosynthesis in Ammonium-grown Azotobacter beijerinckii
}

\author{
By ALAN C. WARD,*BERNARD I. ROWLEY AND \\ EDWIN A. DAWES \\ Department of Biochemistry, University of Hull, Hull HU6 ${ }_{7} R X$
}

(Received 21 March 1977)

\begin{abstract}
Azotobacter beijerinckii synthesized up to $70 \%$ of its dry weight as poly- $\beta$-hydroxybutyrate when grown in batch or oxygen-limited chemostat cultures on a glucose/ammonium salts medium. In a series of steady states during transition from oxygen to ammonium limitation and at different dilution rates in the chemostat, the poly- $\beta$-hydroxybutyrate content of the organism decreased to a minimum of 5 to $10 \%$ of the dry weight at an oxygen inflow rate of $\mathrm{I} \cdot 25 \%(\mathrm{v} / \mathrm{v})$ in $400 \mathrm{ml}$ argon $\mathrm{min}^{-1}$. At higher dissolved oxygen tensions the polymer content increased to a new maximum of 20 to $40 \%$ of the dry weight, depending upon the dilution rate, before declining to a negligible value. In contrast, nitrogen-grown organisms displayed a steady decrease in polymer content with increasing oxygen concentration. This difference in behaviour is attributed to the greater demand for reducing power and ATP by nitrogen-fixing cultures preventing the operation of respiratory control which, it is suggested, occurs in ammonium-grown cultures over a limited range of oxygen supply rates until respiratory protection and uncoupled electron transport intervene.
\end{abstract}

\section{INTRODUCTION}

Poly- $\beta$-hydroxybutyrate (PHB) is a specialized reserve of carbon and energy which accumulates in a variety of micro-organisms under appropriate conditions of nutrient limitation (Dawes \& Senior, 1973). The regulation of PHB metabolism in Azotobacter beijerinckii utilizing glucose as the carbon and energy source under nitrogen-fixing conditions was investigated by Senior \& Dawes (I97I, I973). Chemostat studies revealed that oxygen limitation initiated the accumulation of the polymer in this organism (Senior et al., I972) and that relaxation of an oxygen limitation led to an immediate decrease in the PHB content (Senior \& Dawes, 1973; Jackson \& Dawes, 1976).

To clarify the relationship between oxygen and nitrogen limitation with respect to the control of PHB production we have extended these studies to ammonium-grown organisms. Growth on a supply of fixed nitrogen should exclude the possibility, suggested by Dalton \& Postgate (1969), of an internal nitrogen limitation associated with nitrogen fixation persisting in cultures apparently limited by other factors. Further, the problem of the deleterious effect of oxygen on nitrogenase activity (Parker, I954; Phillips \& Johnson, 196I ; Drozd \& Postgate, 1970) is eliminated, and the control and determination of oxygen and nitrogen limitation is simplified.

We now report that although the general relationship between oxygen limitation and PHB accumulation observed with nitrogen-fixing organisms holds with ammonium-grown bacteria, there is an interesting difference at very low oxygen supply rates.

* Present address: Department of Microbiology, The Medical School, The University, Newcastle-uponTyne, NEI 7 RU. 


\section{METHODS}

Organism. The organism was a capsuleless variant of Azotobacter beijerinckii NCIB9067 isolated by Senior et al. (1972) and now deposited as NCIBI 1292.

Culture methods. The organism was maintained and grown as described by Senior et al. (1972), except that for batch culture experiments the glucose concentration in the growth medium was $12.5 \mathrm{~g} \mathrm{I}^{-1}$, and for continuous culture, media contained $0.15 \mathrm{~g} \mathrm{NH}_{4} \mathrm{Cl} \mathrm{l}^{-1}$ unless indicated to the contrary. The $500 \mathrm{ml}$ culture vessel was fitted with baffles, and a voltage stabilizer was used to control mains voltage fluctuations which otherwise affect the stirrer speed (held at $1000 \mathrm{rev} . \mathrm{min}^{-1}$ in this work) and hence the efficiency of gas transfer into the culture.

Gas regulation and analysis. The supply of oxygen and argon to the culture vessel was measured by rotameters (Series I I00, $300 \mathrm{~mm}$; GEC Elliott Automation, Croydon, Surrey) and the total gas flow was determined by a rotary gas meter (Lange, Gelsenkirchen; Fisons Scientific Apparatus). In a second series of experiments (see text), oxygen was supplied via a peristaltic pump (type MHRE 22; Watson-Marlow, Falmouth, Cornwall), taking precautions to avoid the possibility of oscillations being set up.

The oxygen content of the inflowing and effluent gases was determined by a paramagnetic oxygen analyser (Servomex OA 137; Servomex Controls, Crowborough, Sussex) and $\mathrm{CO}_{2}$ was determined by an infrared analyser (Lira model 300; Mine Safety Appliances, Glasgow). The gases were dried prior to analysis by passage over silica gel.

Analyses. Glucose and ammonia in the inflowing medium and in the supernatant fluid from centrifuged culture samples were determined, respectively, by the glucose oxidase method (Boehringer) and by the method of Chaney \& Marbach (1962); precautions were taken to exclude extraneous ammonia from the environment. Poly- $\beta$-hydroxybutyrate in whole culture samples was determined by the glass-fibre disc modification (Ward \& Dawes, 1973) of the Slepecky \& Law (1960) technique, and carbohydrate was determined in twice-washed organisms from duplicate $10 \mathrm{ml}$ samples by the method of Trevelyan \& Harrison (1952) using glucose as standard. For protein assays, samples ( $\mathrm{ml}$ ) were treated with $5 \mathrm{M}-\mathrm{NaOH}(2 \mathrm{ml})$ in a boiling water bath for $5 \mathrm{~min}$ then cooled and neutralized with $5 \mathrm{M}-\mathrm{HCl}(2 \mathrm{ml})$. Portions ( $\mathrm{I} \mathrm{ml}$ ) were analysed according to Lowry et al. (195I), using corresponding culture supernatant samples as blanks, and dried bovine serum albumin as a standard. Bacterial dry weights were initially determined as described by Senior et al. (1972) but, subsequently, duplicate $10 \mathrm{ml}$ samples of culture were centrifuged in tared, tapered glass centrifuge tubes, washed once with water and dried for $12 \mathrm{~h}$ at $80^{\circ} \mathrm{C}$. Tubes were cooled for $2 \mathrm{~h}$ in a desiccator before weighing.

The viability of chemostat cultures was measured by a slide culture method similar to that of Postgate, Crumpton \& Hunter (196I). Stainless steel annuli on glass slides were completely filled with filtered Difco nutrient agar with"added glucose $\left(20 \mathrm{~g} \mathrm{1}^{-1}\right)$. Culture samples were diluted Io-fold with fresh medium, to prevent loss in viability due to osmotic damage (Smith \& Wyss, 1969), then spread on agar films with Pasteur pipettes. Coverslips were omitted but slides were placed in Petri dishes containing moist cotton wool. The dishes were placed in McIntosh-Fildes jars which also contained damp cotton wool. Microcultures grew both in air and in the effluent gas from the chemostat (oxygen content about I \%). Counts were made after incubation for $8 \mathrm{~h}$ at $30^{\circ} \mathrm{C}$.

\section{RESULTS AND DISCUSSION}

Azotobacter beijerinckii NCIB9067 accumulated some $70 \%$ of its dry weight as PHB when fixing nitrogen in batch culture (Stockdale, Ribbons \& Dawes, I968). A spontaneous variant, NCIBI I 292, lacking the capsule of the parent organism, accumulated up to $50 \%$ of its dry weight as PHB under nitrogen-fixing, oxygen-limiting continuous culture conditions (Senior et al., 1972). However, when grown in batch culture this organism resembled the parent strain accumulating at least $70 \%$ of its dry weight as PHB under nitrogen-fixing conditions or when supplied with ammonium as the nitrogen source (Fig. I). These cultures became oxygen-limited [undetectable dissolved oxygen tension (d.o.t.)] at about the time of transition from exponential growth which also coincided with an increase in the rate of PHB accumulation. Growth in the chemostat at very low oxygen supply rates was therefore studied to see whether the high PHB content characteristic of batch cultures occurred.

The general characteristics of growth of $A$. beijerinckii in continuous culture with ammonium chloride as the nitrogen source were examined under conditions of oxygen and nitrogen limitation. Figures 2 and 3 reveal a similar pattern to that observed by Senior et al. (1972) for nitrogen-fixing cultures. Ammonium-limited organisms contained very low 


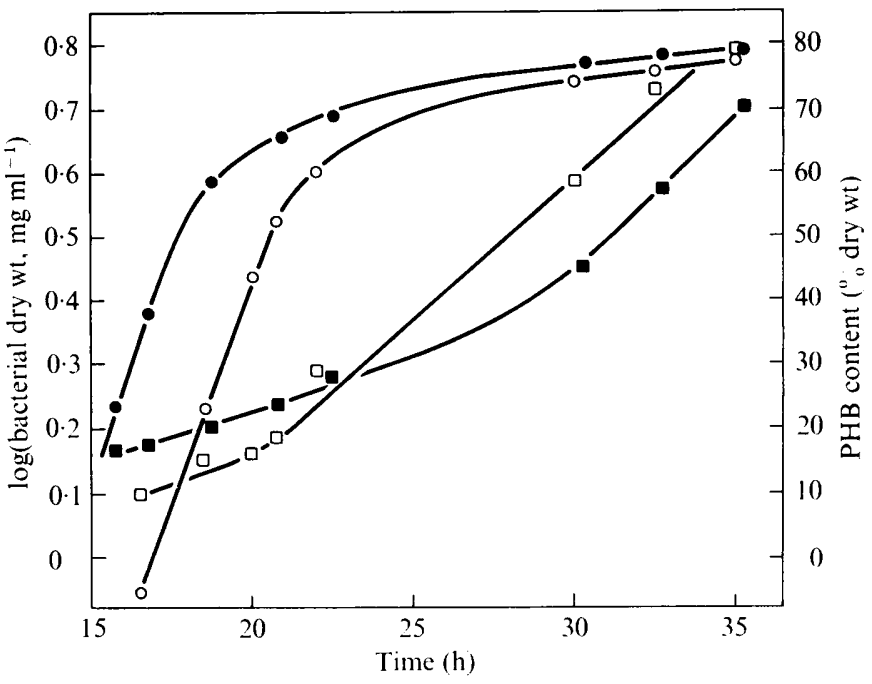

Fig. I. Growth and poly- $\beta$-hydroxybutyrate accumulation of $A$. beijerinckii in batch culture with molecular nitrogen or ammonium as the nitrogen source. $\bigcirc, \bigcirc$, Bacterial dry weight; $\square, \boldsymbol{\square}, \mathrm{PHB}$ content. $\bigcirc, \square, \mathbf{N}_{2}$-grown organisms; $, \mathbf{\square}, \mathrm{NH}_{4}{ }^{+}$-grown organisms.

\section{Table I. Effect of very low oxygen supply rates on the PHB content of ammonium-grown $A$. beijerinckii at different dilution rates}

Oxygen was supplied at between I and $3.3 \mathrm{ml} \mathrm{min}^{-1}$ in $400 \mathrm{ml}$ argon $\mathrm{min}^{-1}$; the d.o.t. was zero throughout. All the variables which might have affected gas transfer were held constant. The individual PHB values represent the average of six determinations with an S.E.M. of $\pm 2 \%$ of the dry weight and refer to steady states in separate experiments.

\begin{tabular}{|c|c|c|c|c|c|c|c|}
\hline $\begin{array}{l}\text { Dilution } \\
\text { rate }\left(\mathrm{h}^{-1}\right)\end{array}$ & $\begin{array}{c}\text { Oxygen } \\
\text { in } \\
\text { inflowing } \\
\text { gas }(\%)\end{array}$ & $\begin{array}{l}\text { PHB } \\
\text { content } \\
\text { (o dry } \\
\text { wt) }\end{array}$ & $\begin{array}{l}\text { Biomass* } \\
\left(\mathrm{mg} \mathrm{ml}^{-1}\right)\end{array}$ & $\begin{array}{l}\text { Dilution } \\
\text { rate }\left(\mathrm{h}^{-1}\right)\end{array}$ & $\begin{array}{l}\text { Oxygen } \\
\text { in } \\
\text { inflowing } \\
\text { gas }(\%)\end{array}$ & $\begin{array}{l}\text { PHB } \\
\text { content } \\
\text { ( } \% \text { dry } \\
\text { wt) }\end{array}$ & $\begin{array}{l}\text { Biomass* } \\
\left(\mathrm{mg} \mathrm{ml}^{-1}\right)\end{array}$ \\
\hline \multirow[t]{3}{*}{0.09} & 0.25 & $\begin{array}{l}39 \cdot 5 \\
39 \cdot 0\end{array}$ & $\begin{array}{l}0.55 \\
0.59\end{array}$ & 0.15 & 0.25 & $\begin{array}{l}6 \mathrm{I} \cdot 5 \\
60 \cdot 0\end{array}$ & $\begin{array}{l}0.21 \\
0.29\end{array}$ \\
\hline & 0.38 & $\begin{array}{l}27 \cdot 0 \\
26 \cdot 0\end{array}$ & $\begin{array}{l}0.81 \\
0.79\end{array}$ & & 0.42 & $\begin{array}{l}40 \cdot 0 \\
39 \cdot 0\end{array}$ & $\begin{array}{l}0.52 \\
0.52\end{array}$ \\
\hline & $0.5 \mathrm{I}$ & $\begin{array}{l}17 \cdot 5 \\
14 \cdot 0\end{array}$ & $\begin{array}{l}I \cdot 10 \\
0.96\end{array}$ & & 0.67 & $\begin{array}{l}22 \cdot 0 \\
20 \cdot 0\end{array}$ & $\begin{array}{l}1 \cdot 00 \\
0.90\end{array}$ \\
\hline \multirow[t]{3}{*}{0.105} & $\begin{array}{l}0.33 \\
0.48\end{array}$ & $\begin{array}{l}29 \cdot 5 \\
14 \cdot 0\end{array}$ & $\begin{array}{l}0.60 \\
0.77\end{array}$ & 0.18 & 0.275 & $\begin{array}{l}73 \cdot 0 \\
70 \cdot 0\end{array}$ & $\begin{array}{l}0.16 \\
0.18\end{array}$ \\
\hline & & & & & 0.475 & $\begin{array}{l}52 \cdot 5 \\
50 \cdot 0\end{array}$ & $\begin{array}{l}0.53 \\
0.54\end{array}$ \\
\hline & & & & & $0.8 \mathrm{I}$ & $\begin{array}{l}17.0 \\
15.0\end{array}$ & $\begin{array}{l}I \cdot 12 \\
I \cdot 08\end{array}$ \\
\hline
\end{tabular}

levels of PHB (Fig. 3); oxygen-limited cultures showed a decreased PHB content at increased specific growth rates (Fig. 2) but under these conditions the maximum PHB content was about $50 \%$ of the dry weight.

As the difference in PHB content observed with batch and chemostat ammonium-grown cultures (Figs I and 2) was believed to be a function of the severity of oxygen limitation, growth in the chemostat at very low oxygen supply rates was studied (Table I). In a succession of steady states the PHB content of the organism fell as the oxygen supply was increased with ammonium as the sole nitrogen source at four different dilution rates $(D)$. The biomass 


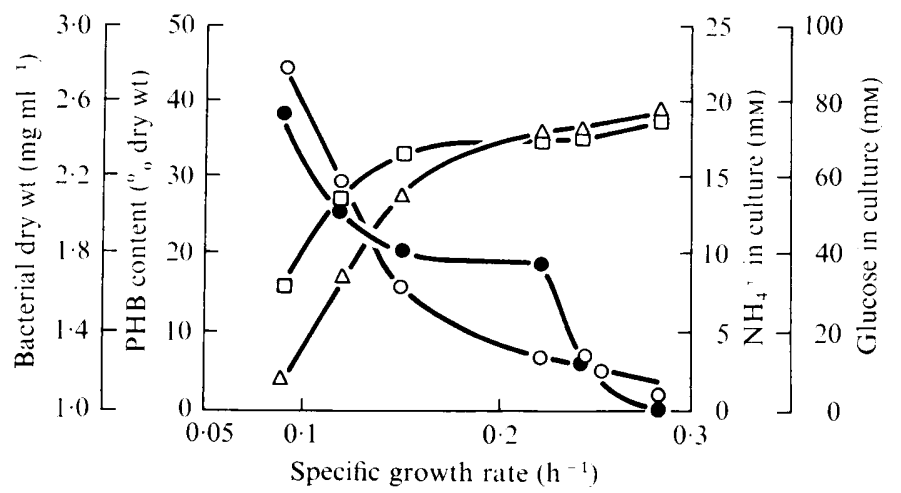

Fig. 2. Characteristics of ammonium-grown, oxygen-limited $A$. beijerinckii in continuous culture. The medium contained $28 \cdot 3 \mathrm{mM}-\mathrm{NH}_{4} \mathrm{Cl}$. The $\mathrm{O}_{2} /$ argon gas mixture contained $\mathrm{I} \cdot 75 \% \mathrm{O}_{2}$ and the total gas flow was $400 \mathrm{ml} \mathrm{min}^{-1}$. The d.o.t. was zero throughout. $\bigcirc$, Bacterial dry weight; $\bigcirc, \mathrm{PHB}$ content; $\square$, glucose in culture supernatant; $\triangle, \mathrm{NH}_{4}+$ in culture supernatant.

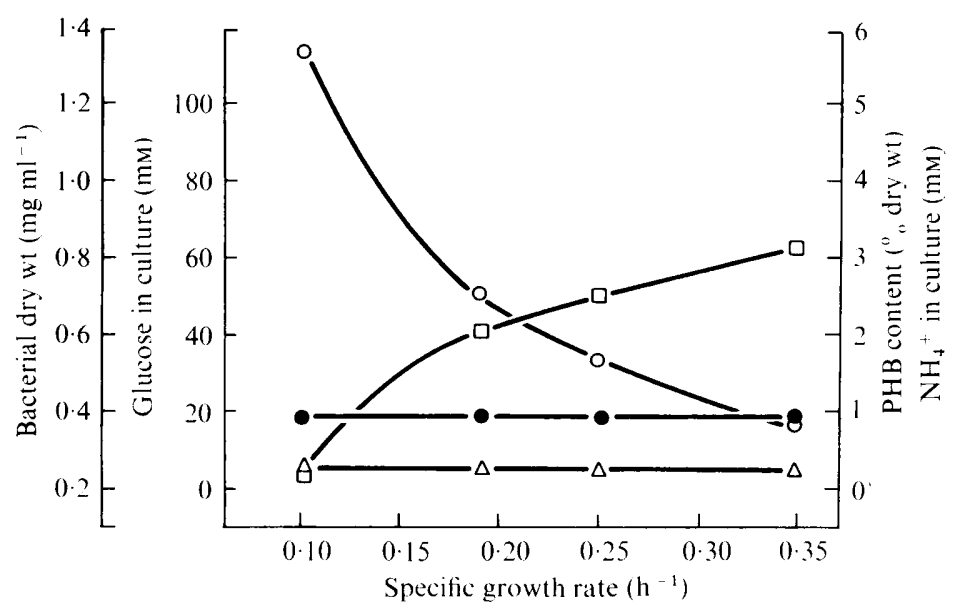

Fig. 3. Characteristics of ammonium-limited growth of $A$. beijerinckii in continuous culture. The medium contained 9.2 mM- $\mathrm{NH}_{4} \mathrm{Cl}$ and the d.o.t. was maintained at $5 \%$ relative to the d.o.t. of air-saturated medium. Symbols as in Fig. 2.

(dry wt corrected for PHB content) at $D=0 \cdot 18 \mathrm{~h}^{-1}$ varied linearly with overall oxygen consumption between inlet oxygen concentrations of 0.25 and $I \cdot 34 \%$ (Fig. 4); the d.o.t. remained below the limit of detection with a Mackereth (1964) electrode. At the lowest oxygen supply used, PHB contents of about $70 \%$, comparable with those observed in batch culture, were attained.

When the culture was taken through a series of steady states of increasing oxygen supply, it eventually passed from oxygen to ammonium limitation. The PHB content of the organism in response to oxygen supply varied in an unexpected manner (Fig. 4). Thus at $D=0 \cdot 18 \mathrm{~h}^{-1}$ the PHB content decreased regularly from its maximum value of $70 \%$ at the lowest oxygen supply rate to a minimum of about $5 \%$ of the dry weight at an inlet oxygen concentration of $1.25 \%$, then subsequently increased to a peak of $35 \%$ of the dry weight at an inlet oxygen concentration of $2 \%$. Further increase in the oxygen supply resulted in a marked increase in the oxygen consumption of the culture and a decrease in PHB content. To minimize the possibility of selection of a variant under these experimental conditions, oxygen supply rates were not varied in regular sequence and experiments were terminated after three or four steady states. 


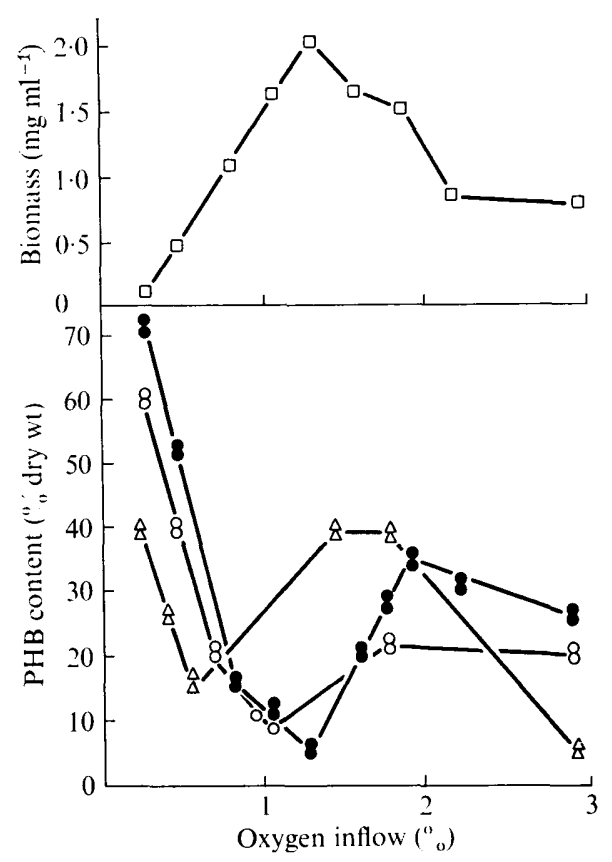

Fig. 4. Effect of oxygen supply and specific growth rate on poly- $\beta$-hydroxybutyrate content and biomass (dry weight corrected for PHB content) of ammonium-grown $A$. beijerinckii. Oxygen/argon mixtures were used and the total gas flow rate was $400 \mathrm{ml} \mathrm{min}^{-1}$. Specific growth rates $\left(\mathrm{h}^{-1}\right): \triangle$, $0.09 ; 0,0.15 ; 0,0.18$. $\square$, Biomass, at $\mu(=D)=0.18 \mathrm{~h}^{-1}$.

The behaviour of $A$. beijerinckii at low oxygen supply rates was re-examined in greater detail in a second series of experiments several months later. During this time the organism had been maintained by serial subculture on nitrogen-free solid medium. The response of the organism was slightly changed as revealed by a shift to the left of the plot of bacterial PHB content versus inlet oxygen concentration, possibly due to a slight alteration in oxygen transfer rate. The overall pattern of the response was, however, similar to that previously observed. Ammonia was undetectable in the culture until the oxygen supply was decreased below $0.35 \%$ and this finding suggests that there is a range of oxygen supply rates where the culture is simultaneously oxygen- and ammonium-limited. The d.o.t. was zero at inlet oxygen concentrations below about $2 \%$, and the culture density depended on the oxygen supply rate below this value, even though ammonia could not be detected in the culture medium. These observations suggest there may be degrees of oxygen limitation when the culture is apparently co-limited by oxygen and ammonium and reinforce the need for a precise definition of oxygen limitation, as stressed by Hine \& Lees (1976) who suggested that the term be used only for oxygen limitation of growth. Other examples of dual limitations involving oxygen have been reviewed by Harrison (I976).

Additional evidence for dual limitation by oxygen and ammonium derives from Fig. 4, where the initial marked decrease in PHB content occurred at all dilution rates as the oxygen supply was increased, even though the cultures were clearly still oxygen-limited since bacterial dry weight was dependent on oxygen supply rate; under a sole oxygen limitation the PHB content would be expected to remain constant. Further, in experiments in which the ammonium concentration was decreased from 0.15 to $0.05 \%$ at $D=0.18 \mathrm{~h}^{-1}$, the effect was equivalent to increasing the oxygen supply, i.e. the plot of PHB content versus 


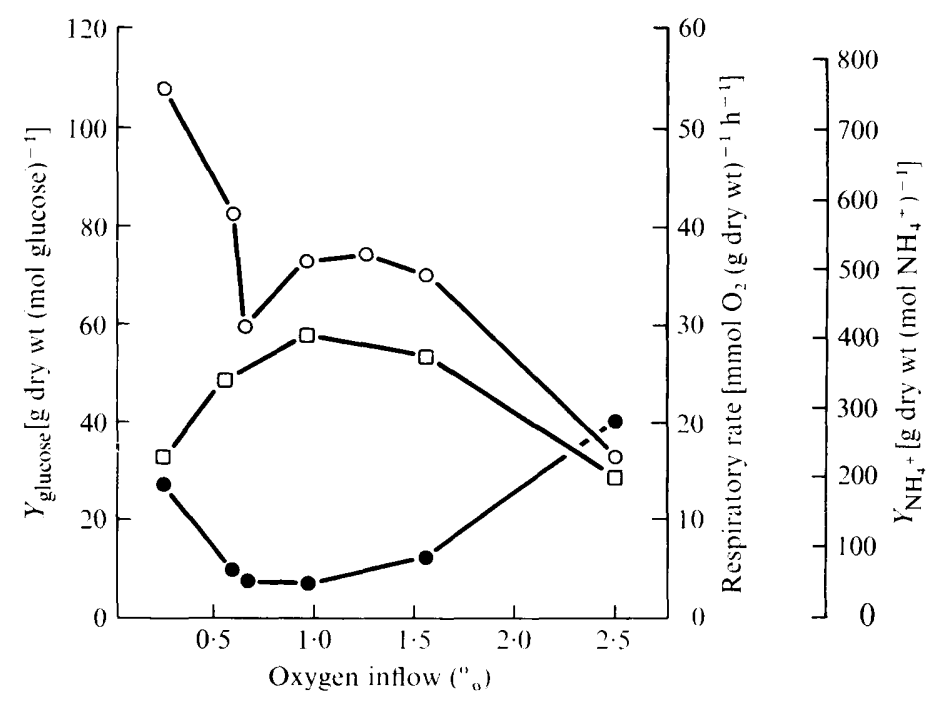

Fig. 5. Effect of oxygen supply on growth yield and respiratory rate of ammonium-grown $A$. beijerinckii. The organism had been maintained on solid medium for several months after the experiments of Fig. 4. Specific growth rate, $\mathrm{O} \cdot \mathrm{I} \mathrm{h}^{-1}$. Oxygen/argon mixtures were used and the total gas flow rate was $400 \mathrm{ml} \mathrm{min}^{-1}$. 0 , Growth yield as $\mathrm{g}$ dry wt (mol glucose) ${ }^{-1} ; \square$, growth yield as $\mathrm{g}$ dry wt $\left(\mathrm{mol} \mathrm{NH}_{4}{ }^{+}\right)^{-1}$;, respiratory rate $\left[\mathrm{mmol} \mathrm{O}_{2}(\mathrm{~g} \text { dry wt})^{-1} \mathrm{~h}^{-1}\right]$.

oxygen supply was moved to the left. The variation between different growth rates seen in the plots of Fig. 4 may thus be explained by changes in ammonium concentration affecting metabolism, reflected by the variations in PHB content which are indicative of changes in the NADH/NAD ${ }^{+}$ratio, in the flow of carbon, and in the acetyl-CoA concentration.

A further important theoretical consideration arising from these experiments is the possibility that transition from oxygen to ammonium limitation altered the $K_{\mathrm{s}}$ (substrate concentration at $0.5 \mu_{\max }$ ) values for both oxygen and ammonium. In Azotobacter the $K_{\mathrm{s}}$ for oxygen could be affected by changes in cytochrome composition of the type recorded by Drozd \& Postgate (1970), Yates \& Jones (1974) and Haaker \& Veeger (1976) and that for ammonium, by changes in the uptake capacity (Kleiner, 1975) or assimilatory mechanism (Nagatani, Shimizu \& Valentine, I97I; Drozd, Tubb \& Postgate, I972).

The peak in biomass (corrected for PHB content) which occurred at about $\mathrm{I} \%$ inlet oxygen concentration (Fig. 4) was not attributable to increased carbohydrate content as this was fairly constant at some $3 \%$ of the dry weight throughout.

Specific rates of in situ oxygen consumption and observed growth yields from glucose and ammonium-nitrogen are recorded in Fig. 5. The viability of the organism remained at about $90 \%$ over the range of oxygen supply rates used and therefore results were not affected by a changing proportion of dead organisms in the culture.

In contrast to the behaviour of ammonium-grown $A$. beijerinckii, under nitrogen-fixing conditions a regular decline in PHB content with increasing d.o.t. was observed and the pattern of decrease/increase/decrease seen in Fig. 4 did not occur.

Azotobacter beijerinckii synthesizes PHB in response to oxygen limitation when assimilating either nitrogen (Senior et al., 1972) or ammonia (Fig. 1). However, with nitrogenfixing organisms, Jackson \& Dawes (I976) observed that transition from oxygen limitation to nitrogen limitation resulted in a steady state PHB content of $10 \%$ of the dry weight, which decreased to $2.5 \%$ when the d.o.t. was doubled. These changes from oxygen to nitrogen limitation were accompanied by marked increases in the levels of NADH oxidase, isocitrate dehydrogenase and 2-oxoglutarate dehydrogenase and decreases in the levels of $\beta$-ketothiolase and acetoacetyl-CoA reductase, two of the enzymes involved in PHB synthesis. 
Such results indicate that $A$. beijerinckii may synthesize low levels of PHB in response to nitrogen limitation provided the oxygen supply is restricted; this phenomenon could be explained by the operation of respiratory control by ATP in nitrogen limitation, elevating the $\mathrm{NADH} / \mathrm{NAD}^{+}$ratio with consequent inhibition of citrate synthase and isocitrate dehydrogenase and increase of acetyl-CoA concentration, thus creating conditions which lead to PHB synthesis (Senior \& Dawes, 1973). However, unless the oxygen supply is kept to low values, this sequence of events is disrupted by the operation of respiratory protection which involves uncoupled respiration, as indicated by a marked increase in $Q_{\mathrm{O}_{2}}$ and cessation of respiratory control by ATP. Consequently, PHB synthesis in response to a limitation other than oxygen is not observed in the chemostat unless the oxygen supply is lower than that at which uncoupled respiration occurs. This situation holds for nitrogenfixing cultures of $A$. beijerinckii (Senior et al., 1972) but clearly also applies to conditions of ammonium growth (Fig. 5), probably because the ammonium concentration is insufficient to repress completely the operation of respiratory protection as described by Dalton \& Postgate (1968). Further, the presence of nitrogenase activity in ammonium-limited cultures of Azotobacter chroococcum (Dalton \& Postgate, 1969) and Clostridium pasteurianum (Daesch \& Mortenson, 1972) has been established.

It seems probable that the different behaviour observed with nitrogen-fixing and ammonium-grown $A$. beijerinckii resides primarily in the much greater demand for ATP and for reducing power in nitrogen fixation. Thus, as the oxygen supply to ammoniumgrown, oxygen-limited $A$. beijerinckii is increased, the NADH/NAD ${ }^{+}$ratio will decrease, inhibition of citrate synthase and isocitrate dehydrogenase will be relaxed and the acetylCoA-concentration fall, producing conditions which result in decreased production of $\mathrm{PHB}$ (Senior \& Dawes, 1973; Jackson \& Dawes, 1976). Further increase of oxygen supply leads to an increased respiratory rate and a greater generation of ATP by oxidative phosphorylation. Eventually, however, the PHB content increases which implies some restriction of electron transport, most simply explained by respiratory control, causing carbon and reducing power to be diverted to PHB synthesis. Respiratory control by ATP at site I has been demonstrated in vitro for Azotobacter vinelandii (Yates \& Jones, 1974) although Harrison (1976) has indicated that the ADP content of the facultative organisms Klebsiella aerogenes and Escherichia coli is such that respiratory control would not be expected to operate. Further increase of the oxygen supply ultimately leads to uncoupled respiration, as indicated by the marked increase in $Q_{\mathrm{O}_{2}}$, with the result that PHB synthesis stops and its degradation occurs.

In contrast, under comparable circumstances, the high demand for reducing power and ATP for nitrogenase activity in nitrogen-fixing $A$. beijerinckii probably prevents the ATP concentration attaining a value which would impose respiratory control and so diversion of reducing power to polymer synthesis does not occur. Also, as the oxygen supply is increased further, respiratory protection of nitrogenase is achieved by uncoupled respiration (Jones et al., 1973). The marked increase in $Q_{\mathrm{O}_{2}}$ of ammonium-grown organisms which occurs at the highest d.o.t. values studied might possibly reflect the presence of nitrogenase (although not nitrogen fixation) since the organisms would clearly be nitrogen-limited under these conditions. Alternatively, nitrogen fixation and respiratory control may not be co-ordinately regulated.

We are greatly indebted to the Agricultural Research Council for a grant-in-aid and to Mr I. D. Marriott for technical assistance. We also thank Dr M. P. Stephenson for some experiments with nitrogen-grown organisms. 


\section{REFERENCES}

Chaney, A. L. \& Marbach, E. P. (I962). Modified reagents for determination of urea and ammonia. Clinical Chemistry 8, 130-132.

Daesch, G. \& Mortenson, L. E. (1972). Effect of ammonia on the synthesis and function of the $\mathrm{N}_{2}$-fixing enzyme system in Clostridium pasteurianum. Journal of Bacteriology 110, I03-109.

Dalton, H. \& Postgate, J. R. (I968). Effect of oxygen on growth of Azotobacter chroococcum in batch and continuous cultures. Journal of General Microbiology 54, 463-473.

Dalton, H. \& Postgate, J. R. (1969). Growth and physiology of Azotobacter chroococcum in continuous culture. Journal of General Microbiology 56, 307-3I9.

DAwes, E. A. \& Senior, P. J. (1973). The role and regulation of energy reserve polymers in microorganisms. Advances in Microbial Physiology ro, I35-266.

Drozd, J. \& Postgate, J. R. (1970). Effect of oxygen on acetylene reduction, cytochrome content and respiratory activity of Azotobacter chroococcum. Journal of General Microbiology 63, 63-73.

Drozd, J. W., Tubb, R. S. \& Postgate, J. R. (1972). A chemostat study of the effect of fixed nitrogen sources on nitrogen fixation, membranes and free amino acids in Azotobacter chroococcum. Journal of General Microbiology 73, 22 I-232.

HAAKeR, H. \& VeEger, C. (1976). Regulation of respiration and nitrogen fixation in different types of Azotobacter vinelandii. European Journal of Biochemistry 63, 499-507.

HARRISON, D. E. F. (I976). The regulation of respiration rate in growing bacteria. Advances in Microbial Physiology 14, 243-313.

Hine, P. W. \& LeEs, H. (1976). The growth of nitrogen-fixing Azotobacter chroococcum in continuous culture under intense aeration. Canadian Journal of Microbiology 22, 6 I I-6I8.

JACKsON, F. A. \& DAwES, E. A. (1976). Regulation of the tricarboxylic acid cycle and poly- $\beta$ hydroxybutyrate metabolism in Azotobacter beijerinckii grown under nitrogen or oxygen limitation. Journal of General Microbiology 97, 303-3 I 2.

Jones, C. W., Brice, J. M., Wright, V. \& ACKrell, B. A. C. (1973). Respiratory protection of nitrogenase in Azotobacter vinelandii. FEBS Letters 29, 77-8I.

KLEINER, D. (1975). Ammonium uptake by nitrogen fixing bacteria. I. Azotobacter vinelandii. Archives of Microbiology 104, I63-169.

Lowry, O. H., Rosebrough, N. J., Farr, A. L. \& RANDALl, R. J. (I95I). Protein measurement with the Folin phenol reagent. Journal of Biological Chemistry 193, 265-275.

MACKeRETH, F. J. H. (I964). An improved galvanic cell for determination of oxygen concentration in fluids. Journal of Scientific Instruments 4I, 38-4I.

Nagatani, H., Shimizu, M. \& Valentine, R. C. (1971). The mechanism of ammonia assimilation in nitrogen fixing bacteria. Archiv für Mikrobiologie 79, I64-I75.

PARKer, C. A. (1954). Effect of oxygen on nitrogen fixation by Azotobacter. Nature, London 173, 780-78I.

Phillips, D. A. \& Johnson, M. J. (I96I). Aeration in fermentations. Journal of Biochemical and Microbiological Technology and Engineering 3 , 277-309.

Postgate, J. R., Crumpton, J. \& Hunter, J. R. (I96I). The measurement of bacterial viabilities by slide culture. Journal of General Microbiology 24, I5-24.

Senior, P. J. \& Dawes, E. A. (197I). Poly- $\beta$ hydroxybutyrate biosynthesis and the regulation of glucose metabolism in Azotobacter beijerinckii. Biochemical Journal 125, 55-66.

SENIOR, P. J. \& DAwES, E. A. (I973). The regulation of poly- $\beta$-hydroxybutyrate metabolism in Azotobacter beijerinckii. Biochemical Journal 134, 225-238.

Senior, P. J., Beech, G. A., Ritchie, G. A. F. \& DAWES, E. A. (1972). The role of oxygen limitation in the formation of poly- $\beta$-hydroxybutyrate during batch and continuous culture of Azotobacter beijerinckii. Biochemical Journal 128, I193-I201.

SlePECKY, R. A. \& LAW, J. H. (1960). A rapid spectrophotometric assay of $\alpha, \beta$-unsaturated acids and $\beta$-hydroxy acids. Analytical Chemistry 32, I 697-1699.

Smith, D. D. \& Wyss, O. (1969). The rapid loss of viability of Azotobacter in aqueous solutions. Antonie van Leeuwenhoek 35, 84-96.

Stockdale, H., Ribbons, D. W. \& Dawes, E. A. (I968). Occurrence of poly- $\beta$-hydroxybutyrate in the Azotobacteriaceae. Journal of Bacteriology 95, I798-I803.

Trevelyan, W. E. \& Harrison, J. S. (1952). Fractionation and micro-determination of cell carbohydrates. Biochemical Journal 5o, 298-305.

WARD, A. C. \& DAwES, E. A. (I973). A disk assay for poly- $\beta$-hydroxybutyrate. Analytical Biochemistry 52, 607-6I3.

YATES, M. G. \& Jones, C. W. (1974). Respiration and nitrogen fixation in Azotobacter. Advances in Microbial Physiology 11, 97-I35. 